\title{
POSICIONAMENTO AXIOLÓGICO DAS CONCEPÇÕES DE DIVULGAÇÃO CIENTÍFICA ${ }^{35}$
}

\section{AXIOLOGICAL POSITIONING OF THE CONCEPTUALIZATION OF SCIENCE COMMUNICATION}

Giselle Liana Fetter ${ }^{36}$

\begin{abstract}
Resumo
A divulgação científica tem recebido interesse de muitos pesquisadores da Linguística, que a estudam a partir de diferentes teorias. No Brasil, vários trabalhos dessa área apresentam os argumentos de que os cientistas veem esses gêneros como "distorção" do discurso científico, mas não demonstram dados que comprovem tal afirmação. Assim, este trabalho busca investigar as concepções de divulgação científica com base nos preceitos do Círculo de Bakhtin, analisando o discurso de dois artigos publicados em periódicos científicos no Brasil. Ao considerar a perspectiva do cientista, pode-se compreender se a visão dominante da ciência seria uma realidade na divulgação científica desse país e incentivar, ainda mais, o protagonismo das universidades na produção desses gêneros do discurso.
\end{abstract}

Palavras-chave: Divulgação científica. Ciência. Universidade. Círculo de Bakhtin.

\begin{abstract}
Science communication has drawn the interest of many linguists, who study it based on various theories. In Brazil, several works in this field argue that scientists see these genres as a "distortion" of scientific discourse, but these works do not demonstrate data that support such argument. Therefore, this paper aims to investigate the conceptualization of science communication based on the theoretical assumptions of Bakhtin Circle, analyzing the discourse of two papers published in scientific journals in Brazil. By considering the perspective of the scientist, one may understand if the dominant view of science would be a fact in science communication of the mentioned country and thus encourage a prominent role of universities in the production of theses genres.
\end{abstract}

Keywords: Science Communication. Science. University. Bakhtin Circle.

\footnotetext{
${ }^{35}$ O presente trabalho foi realizado com apoio da Coordenação de Aperfeiçoamento de Pessoal de Nível Superior - Brasil (CAPES) - Código de Financiamento 001.

${ }^{36}$ Doutoranda em Letras na Pontifícia Universidade Católica do Rio Grande do Sul (PUCRS). Membro do grupo de pesquisa Tessitura: Vozes em (Dis)curso. E-mail: gisellerevisora@gmail.com. Telefone: (51)33203676. ORCID https://orcid.org/0000-0002-5577-2214.
} 


\section{RevistAleph}

\section{Introdução}

Os gêneros do discurso da divulgação científica ${ }^{37}$ (doravante denominada DC) correspondem a textos sobre ciência destinados ao público leigo - não especialistas. Geralmente, os estudos sobre DC envolvem textos jornalísticos (MASSARANI; ROCHA, 2018, p. 4), publicados em jornais ou revistas de grande circulação (versões impressa e online). Porém, a DC abrange vários gêneros do discurso como panfletos, folhetos (FETTER, 2017), cartilhas, programas televisivos, atividades em museus, gêneros digitais - blogs, redes sociais, vídeos -, entre outros.

São diversos os estudos e pesquisas sobre a DC. Segundo uma pesquisa realizada por Massarani e Rocha (2017, p. 13) com base no número de artigos publicados em periódicos científicos, houve um aumento do interesse em DC nos últimos anos na América Latina: dos 609 artigos coletados para a pesquisa das autoras, 509 correspondiam a publicações no Brasil. Apesar do crescente interesse pela DC, Massarani e Moreira (2016, p. 1592) identificam alguns desafios a serem enfrentados: o acesso à DC por toda a população brasileira; políticas públicas para o desenvolvimento da DC; e o aperfeiçoamento da qualidade de produção da DC. Contudo, vemos que há outras questões a serem consideradas e para as quais os estudos proporcionados pela área da Linguística ainda podem colaborar.

Em 1990 e 2003, respectivamente, Stephen Hilgartner e Greg Myers - professores de universidades estadunidenses - publicaram artigos ${ }^{38}$ sobre a DC, em que afirmam existir uma "visão dominante" que caracteriza o discurso científico como "genuíno" enquanto a DC seria concebida como um discurso "pejorativo" ou como uma "distorção" do conhecimento científico. Conforme Hilgartner (1990, p. 535), a "distorção" corresponderia ao uso de afirmações equivocadas que alterariam o conhecimento científico, tornando-o, até mesmo, inútil.

É provável que haja questionamentos do porquê resgatar artigos de 30 anos atrás. Esta pesquisa se justifica nesse sentido. Há diversos trabalhos de linguistas brasileiros que pesquisam a divulgação científica no Brasil que apresentam os argumentos de Hilgartner

\footnotetext{
${ }^{37}$ Há outros termos para se referir à divulgação científica, como por exemplo, popularização da ciência, jornalismo científico e comunicação da ciência. Segundo pesquisa de Massarani e Rocha (2018), o termo divulgação científica foi aplicado em 72\% dos artigos pesquisados entre os anos de 1980 e 2016 . Por essa razão, nesta pesquisa, utilizaremos divulgação científica.

${ }^{38}$ A referência completa dos artigos encontra-se na seção Referências.
} 


\section{RevistAleph}

(1990) e Myers (2003) sobre a visão dominante. Os linguistas afirmam existir tal visão na ciência brasileira (FETTER, 2020). Contudo, não são apresentados dados estatísticos que demonstrem que essa visão também se aplicaria à realidade da DC no Brasil. Como mencionamos, há uma considerável diferença temporal entre a data de publicação dos artigos de Hilgartner (1990) e Myers (2003) e os dias atuais. Segundo Massarani e Rocha (2017, p. 23), as pesquisas em DC atingiram seu pico entre os anos de 2013 e 2015, o que pode indicar uma mudança em relação à representação da DC para a ciência.

Nossa motivação em realizar esta pesquisa possui sua essência na Filosofia da Linguagem, mais especificamente, nos preceitos do Círculo de Bakhtin, na "natureza ativamente responsiva" do discurso (BAKHTIN, 2016, p. 25). Para Bakhtin (2016, p. 25), o que falamos (escrevemos) predispõe uma resposta, tanto imediata quanto retardada. Há, no enunciado, uma intrínseca "possibilidade de responder a ele", como uma resposta crítica, como "influência educativa sobre os leitores, sobre suas convicções" (BAKHTIN, 2016, p. 34-35). Esta pesquisa, que faz parte de um projeto de doutorado em andamento, foi concebida como uma resposta aos argumentos de que haveria, no Brasil, a visão dominante da ciência, para a qual a DC seria um discurso depreciativo do conhecimento científico. Identificamos que há uma lacuna de pesquisas que tenham como objeto de estudo os discursos dos cientistas em relação às concepções de DC. Conforme Bakhtin (2017, p. 41), os sentidos são revelados quando colocados em contato com o sentido do outro, como um diálogo.

O presente artigo busca analisar as concepções de DC, a partir de um breve corpus composto por artigos científicos de professores-pesquisadores ${ }^{39}$. Assim, selecionamos dois recortes de artigos científicos: um publicado em um periódico em estudos de linguagem e outro publicado em um periódico de estudos de Biologia. Este estudo preliminar tem por objetivo analisar os discursos de dois professores-pesquisadores de universidades brasileiras e comparar as concepções da DC feitas em cada um deles.

Este artigo está organizado em quatro seções além desta Introdução. Na próxima seção, discorreremos sobre o argumento a respeito da visão dominante da ciência, demonstrando como os pressupostos teóricos do Círculo de Bakhtin podem colaborar para

39 Em nossa pesquisa, aplicaremos a denominação professor-pesquisador em vez de cientista, pois analisaremos as concepções de DC exclusivamente nas universidades brasileiras. Entendemos que cientista seria um termo mais genérico que pode ser empregado também para pesquisadores que trabalham em instituições destinadas apenas à pesquisa, que não são nosso foco. 


\section{RevistAleph}

o objeto de estudo que motiva este trabalho. Na terceira seção, discorreremos sobre a análise do artigo publicado no periódico de estudos da Biologia. A quarta seção está dedicada à análise do artigo no periódico de estudos da linguagem, na qual apresentaremos alguns aspectos contrastivos entre os artigos. Por fim, nas considerações finais, traremos alguns apontamentos acerca da análise e do desenvolvimento de trabalhos futuros.

\section{Orientação avaliativa da visão dominante da ciência}

A orientação avaliativa, presente no título desta seção, é um dos princípios trazidos na obra Marxismo e Filosofia da Linguagem de Volóchinov (2017, p. 233). Assim, iniciamos esta seção, pois entendemos que o argumento de Hilgartner (1990) e Myers (2003) sobre a existência de uma visão dominante da ciência possui um tom valorativo. Ao longo desta seção, discorreremos sobre alguns princípios apresentados pelo Círculo de Bakhtin com o intuito de delinear a reflexão acerca dos estudos sobre a visão dominante, que motivam esta pesquisa.

Segundo Volóchinov (2017, p. 236, grifo do autor), "todo enunciado é antes de tudo uma orientação avaliativa". Para o autor, todos os elementos que compõem um enunciado foram escolhidos a partir desse tom valorativo. Afirmar que há uma visão dominante que vê a DC como um discurso "distorcido" já situa a ciência - os cientistas - em uma posição de domínio, ou seja, Hilgartner (1990) e Myers (2003) atribuem à ciência a superioridade do conhecimento científico.

É possível que existam cientistas, no Brasil, que consideram a DC um discurso impreciso e que, ao se oporem a ela, consequentemente, também estão atribuindo um tom valorativo. Precisaríamos de dados contextuais que pudessem corroborar essa suspeita. Porém, Hilgartner (1990) e Myers (2003) não os fornecem, tornando a visão dominante da ciência um fato. Além disso, quando os trabalhos sobre DC, no Brasil, apresentam o argumento de que há uma visão dominante, atribuem a ela um aspecto factual para o contexto histórico desse país. Apesar de Myers (2003) apontar para uma concepção mais atual sobre a DC que refuta a visão dominante, entendemos que, se essa visão está sendo contraposta, o autor dá indícios de que ela faz parte do meio científico. Além disso, ao longo de seu artigo, Myers (2003) faz referência à visão dominante, trazida por Hilgartner, delineando as posições que essa visão assume em relação à DC. Myers (2003, p. 266) ainda 


\section{RevistAleph}

fala em visão canônica, apresentada por Grundmann e Cavaillé (2000, p. 353). Esses autores, por sua vez, também citam Hilgartner (1990). Vemos, assim, que o argumento desse autor foi e, ainda, é replicado em outros trabalhos.

Recorremos a trabalhos científicos citados por Hilgartner (1990) para verificar se haveria algum estudo anterior ao seu artigo que justificasse a posição do autor em relação à ciência. Hilgartner (1990) cita um trabalho de Jeremy Green (1985), em que este autor trata da visão dominante como mito. Porém, ao chamar de "mito", ele esclarece que há uma "forte representação ideológica da realidade" (GREEN, 1985, p. 139, tradução nossa). Em outras palavras, ele acredita que o mito da DC como "poluição" faz parte da ideologia corporativa dos cientistas, mas não apresenta dados que corroborem sua afirmação. Poderíamos prosseguir nossa pesquisa sobre as referências desses autores, recorrendo a outros trabalhos anteriores ao de Green para verificarmos o argumento de Hilgartner (1990), mas observamos que, estaríamos, cada vez mais, afastando-nos do contextual histórico do século XXI, para o qual a DC desperta grande interesse de estudo (MASSARANI; ROCHA, 2017, p. 33).

Uma enunciação é composta, conforme Volóchinov (2013, p. 157), por duas partes: a parte verbal e o subentendido. Contudo, Volóchinov (2013, p. 157-158) ressalta que o subentendido não é algo psíquico, e sim social; ele é uma "unidade material do mundo", do horizonte dos falantes. Trata-se de uma comunidade de valorações que integra os indivíduos em algum grupo social. As valorações não são um ato individual, mas realizamse no indivíduo apoiadas nos outros indivíduos, no grupo a que pertencem. Complementarmente, Bakhtin (2016, p. 47) explica que, além das escolhas linguísticas do falante, o enunciado é determinado pelo elemento expressivo: "um enunciado absolutamente neutro é impossível”. Para Bakhtin (2016, p. 47), as escolhas dos elementos linguísticos que compõem um enunciado são ocasionadas pelas valorações. Cada palavra reflete uma "posição socialmente determinada" (VOLOCHÍNOV, 2013, p. 198), mas também há "um cruzamento de acentos" (VOLÓCHINOV, 2017, p. 113) que a palavra refrata, pois o "signo é vivo e móvel e é capaz de desenvolvimento" (VOLOCHÍNOV, 2013, p. 199).

Volochínov (2013, p. 82) acrescenta que não há limites para o tamanho desse grupo e, no caso dos trabalhos científicos que ainda apontam a visão dominante de Hilgartner (1990), podemos observar que as valorações também persistem ao longo de décadas. Segundo Volochínov (2013, p. 80), o horizonte dos falantes amplia-se no espaço e 


\section{RevistAleph}

no tempo. A ausência de pesquisas científicas que comprovem alguma premissa pode, em certos estudos, tornar as valorações "cada vez mais constantes" dentro de um grupo social e podem perdurar por "épocas totais" (VOLOCHÍNOV, 2013, p. 80) como ocorre com a questão da visão dominante.

Observamos que há um "coral de apoio", aspecto apontado por Volochínov (2013, p. 82) para tratar das valorações subentendidas de um determinado grupo, que compartilha o(s) mesmo(s) ponto(s) de vista, que concordam e aceitam certo discurso. Esse "coral" seria formado, no contexto de nosso trabalho, pelos autores de artigos, no Brasil, que enunciaram a existência de uma visão dominante da ciência com base em Hilgartner (1990) e/ou Myers (2003).

Segundo Volochínov (2013, p. 82), quando não há "coral de apoio", a valoração pode tomar outro caminho: "talvez, assumir tonalidades de desafio ou de irritação para com o ouvinte, ou finalmente, ser deslocada e reduzida ao mínimo". Porém, o que aparentemente acontece, no caso do argumento sobre a visão dominante, é que várias pesquisas reforçam essa valoração. Como mencionamos, há um vasto espaço de tempo da publicação do artigo de Hilgartner (1990), mas seu tom valorativo a respeito da ciência ainda ressoa nos estudos atuais.

Esse ressoar de discursos e valorações revela o caráter dialógico do discurso apontado nos estudos do Círculo de Bakhtin. Conforme Zago e Di Fanti (2008, p. 195), o dialogismo é "um princípio constitutivo da linguagem que pressupõe que todo discurso é constituído por outros discursos, instaurando uma dinamicidade permanente". Volóchinov (2017, p. 184) explica que qualquer enunciado é uma resposta a algo: "ele é um elo na cadeia ininterrupta de discursos verbais". Segundo o autor, o enunciado seria uma continuação de enunciados anteriores, que "espera por uma compreensão ativa e responsiva" (VOLÓCHINOV, 2017, p. 184). Da mesma forma, Bakhtin (2016, p. 92) coloca que as relações dialógicas estão em todos os enunciados, e precisamos da linguagem para perceber essas relações. No entanto, elas não se encontram no sistema da língua, como meros objetos, elas estão "entre toda espécie de enunciados na comunicação discursiva" (BAKHTIN, 2016, p. 92).

Para verificarmos a existência de uma visão dominante, não podemos considerar apenas as afirmações trazidas pelos autores já mencionados, pois elas são apenas parte de um todo que envolve também os próprios cientistas. Sobre a perspectiva dos cientistas, no 


\section{RevistAleph}

artigo de Hilgartner (1990), há um estudo sobre as causas do câncer, que teria causado bastante repercussão, devido à má-interpretação dos dados da pesquisa. Green (1985) toma o mesmo caminho em seu artigo, porém a respeito de uma pesquisa no campo da citogenética humana. Já Myers (2003) concentra-se nas diferenças de linguagem entre DC e discurso científico, mas sempre remetendo à existência da visão dominante. Os autores (Hilgartner e Green) trazem apenas um caso em que a DC aparentemente teria causado uma "distorção" do discurso científico, suscitando a crítica de alguns cientistas das respectivas áreas, enquanto Myers (2003, p. 266) apoia-se nos argumentos de Hilgartner (1990). O que queremos demonstrar com esses apontamentos é que a existência de uma visão dominante da ciência é fundamentada com base em relatos de alguns casos. Entendemos que os autores utilizam esses casos para ilustrar a opinião dos cientistas sobre a DC, mas o caminho percorrido em seus trabalhos é de que haveria um consentimento no meio científico a respeito da DC como "distorção".

Conforme Bakhtin (2016, p. 29), há a "alternância dos sujeitos do discurso": os enunciados se constituem por enunciados anteriores de outros e por enunciados que os respondem. O que determina a conclusibilidade do enunciado é a capacidade de responder a ele. Mesmo uma obra, aparentemente acabada, está sujeita à resposta do outro. Essa resposta, por sua vez, pode vir como um texto em resposta a outro texto como "um contato dialógico entre textos" (BAKHTIN, 2017, p. 67). Não podemos considerar a visão dominante como um fato na ciência do Brasil e apropriarmo-nos nessa verdade, concebendo-a de forma acabada e impossibilitada de resposta, pois "o enunciado constrói-se em determinado momento social e histórico e, com isso, toca em diferentes fios dialógicos existentes" (DI FANTI, 2003, p. 108). Dessa forma, quando os trabalhos em DC apresentam os argumentos de Hilgartner (1990) e/ou Myers (2003) para abordar a relação da DC com a ciência no Brasil, apropriam-se de um discurso que não reflete o posicionamento dos cientistas nesse país, mesmo que, de alguma forma, essa realidade possa se enquadrar no caso do Brasil, que é o que queremos verificar.

Conforme Volochínov (2013, p. 165), nosso discurso interno - nosso pensamento - também está repleto de dialogismo. Quando refletimos sobre algo, nosso pensamento estabelece intervenções de pergunta e resposta. Essas intervenções "estão totalmente impregnadas com a valoração de um ouvinte potencial, de um auditório potencial" (VOLOCHÍNOV, 2013, p. 164). Para o autor, esse dialogismo pode ser claramente observado 


\section{RevistAleph}

quando precisamos tomar uma decisão, como se nossa consciência assumisse duas vozes que se contrapõem. Porém, uma dessas vozes "coincide com a visão, com as opiniões e com as valorações da classe a que pertencemos" (VOLOCHíNOV, 2013, p. 165). Há uma valoração entre os pesquisadores de DC quando afirmam que os cientistas possuem uma ideologia dominante que refuta esse gênero do discurso. Assim, forma-se um grupo social com determinadas "valorações que vão impregnando a consciência" (VOLOCHínOV, 2013, p. 98, grifo do autor). A consciência é vista "não apenas como um fenômeno psicológico, mas, acima de tudo, é um fenômeno ideológico, é um produto da comunicação social" (VOLOCHÍNOV, 2013, p. 98, grifo do autor).

Para Bakhtin (2015), todo enunciado está impregnado de discursos alheios discursos do outro - e envolve-se de opiniões e avaliações alheias. Esse outro, explica Di Fanti (2003, p. 98), habita o discurso em diferentes graus "[...] às vezes é visível, às vezes está escondido, mas sempre está lá; constitui um princípio alteritário". Sendo assim, como já mencionamos, o enunciado não é visto como algo acabado, mas em construção (DI FANTI, 2003, p. 98). Conforme Bakhtin (2016, p. 147), podemos falar dos enunciados alheios, mas “[...] não podemos deixar de ocupar alguma posição dialógica em relação a ele, concordar e discordar dele, assumir diante dele uma posição polêmica, irônica, apresentá-la como uma posição verdadeira, de autoridade, duvidosa etc.". Atribuímos, claramente, a questão da visão dominante presente nos artigos sobre a DC como um discurso de Hilgartner (1990) e/ou de Myers (2003). O outro, nesse caso, está visível para nós. A questão que nos cerca sobre os argumentos de que há uma visão dominante é justamente podermos tomar uma posição, que só é possível uma vez que analisarmos se essa ideologia da ciência está, de fato, presente nos discursos dos cientistas no Brasil. Como explica Bakhtin (2016, p. 148), não podemos nos abstrair da totalidade para não deixarmos "de ouvir todos os harmônicos dialógicos". Complementarmente, Di Fanti (2003, p. 101) expõe que:

[...] a linguagem a partir da abordagem dialógica não pode ser estudada fora da sociedade, uma vez que o enunciado, como unidade concreta da interação verbal, tem estabilidade provisória e traz em sua constituição características de cada situação de enunciação em que é produzido e circula.

Percebemos que os discursos de Hilgartner (1990) e Myers (2003), ao circundarem os trabalhos sobre DC no Brasil, tendem a guiar as pesquisas a respeito do tema como uma forma de embate com a ciência, pois elas já partem do pressuposto - subentendido - de 


\section{RevistAleph}

que os cientistas consideram esse gênero uma "distorção". Consideramos de crucial relevância observar como a DC é conceitualizada nos discursos dos cientistas no Brasil neste momento histórico. Segundo Volochínov (2013, p. 197), “uma mesma palavra [e aqui podemos associar a DC] nos lábios de pessoas de classes distintas reflete também pontos de vista distintos, mostra relações diferentes com a mesma realidade [...]". Nas palavras de Di Fanti (2003, p. 101), o enunciado "[...] instaura-se diferentemente em cada interação".

De acordo com Volochínov (2013, p. 168, grifo do autor), "todo discurso é dialógico, dirigido a outra pessoa, à sua compreensão e à sua efetiva resposta potencial". A orientação social, explica o autor, diz respeito a uma "correlação sócio-hierárquica" dos interlocutores e ela é inerente a qualquer enunciação. De acordo com Bakhtin (2016, p. 63), nossos enunciados são construídos em função do destinatário, de como nossos discursos são por ele percebidos:

[...] até que ponto ele está a par da situação, dispõe de conhecimentos especiais de um dado campo cultural da comunicação; levo em conta as suas concepções e convicções, os seus preconceitos (do meu ponto de vista), as suas simpatias e antipatias [...] (BAKHTIN, 2016, p. 63).

Os trabalhos sobre DC que autenticam a visão dominante a interpretam a partir de uma perspectiva unilateral, que coloca os cientistas em um plano de distanciamento. Em outras palavras, os cientistas são os representantes da visão dominante e, por isso, não são invocados a contribuir diretamente com a produção de DC. Esses movimentos de interpretação constituem os princípios de excedente de visão e exotopia, que apontam para a importância de contatar o outro, "o sentido do outro" (BAKHTIN, 2017, p. 19), afastandonos daquilo que queremos interpretar. $O$ excedente de visão permite que vejamos o outro a partir de nossa perspectiva. A partir desse excedente proporcionado pelo outro, conseguimos nos ver, conseguimos olhar para o objeto de maneira diferente (exotopia). Nessa relação com o outro, surgem "novos aspectos, novas profundezas do sentido", que nos colocam em um "encontro dialógico" (BAKHTIN, 2017, p. 19), permitindo que compreendamos melhor nossa cultura e a cultura do outro.

Buscamos com esta pesquisa, analisar os discursos dos cientistas sobre a DC como uma maneira de dar conta da situação deste momento social e histórico do Brasil. Dessa forma, nas seções que seguem, apresentaremos os artigos científicos sobre a DC: de uma Linguista e de um Físico. Realizamos um recorte dos artigos, pois este trabalho constituísse 


\section{RevistAleph}

como um gênero do discurso pouco extenso para explorá-los em sua totalidade. Entendemos que as seções dos artigos que selecionamos não são partes isoladas, elas formam um todo dialógico. Por isso, apesar de escolhermos algumas seções, por vezes, faremos referência a outras partes do artigo que foram, à primeira vista, desconsideradas, como forma de demonstrar os sentidos que os autores trazem em relação à DC.

\section{As concepções de DC sob o olhar valorativo da física}

O artigo publicado na Revista da Biologia intitula-se As consequências da má divulgação científica ${ }^{40}$ dos autores Guilherme Brockington ${ }^{41}$ e Lucas Mesquita ${ }^{42}$. A edição da revista em que o artigo se encontra reuniu trabalhos voltados para as neurociências e sua relação com o jornalismo científico. $\mathrm{O}$ artigo em questão tem como objetivo apresentar "algumas consequências da má divulgação científica, [...] algumas dificuldades em se realizar uma forma otimizada de comunicação com o público leigo e [...] algumas abordagens que visam minimizar os possíveis problemas nesse diálogo" (BROCKINGTON; MESQUITA, 2016, p. 29).

Esse artigo está organizado em oito seções: 1) Introdução; 2) As imagens do cientista; 3) As dificuldades da boa divulgação científica; 4) Sarampo: o novo vilão do Reino Mágico de Walt Disney; 5) O inofensivo cinema de domingo: neurociência e a divulgação científica; 6) O interesse na ciência e o papel da má divulgação científica; 7) Mas como fazer uma boa divulgação científica?; e 8) Conclusão. Para a presente análise, desconsideramos a seção 2, por abordar o cientista, as seções 4 e 5, por trazerem relatos de casos em que a DC teria repercutido negativamente, a seção 6, por discorrer sobre a relação da DC com a sociedade, e a conclusão, por apresentar uma síntese do artigo.

Iniciaremos esta análise, voltando nosso olhar para o título do artigo: As consequências da má divulgação científica. Observamos aqui um tom valorativo a respeito

\footnotetext{
40 BROCKINGTON, Guilherme; MESQUITA, Lucas. As consequências da má divulgação científica. Revista da Biologia, v. 15, n. 1, p. 29-34, 2016. Disponível em: [http://www.ib.usp.br/revista/node/207]. Acesso em: 16 jan. 2019.

41 José Guilherme de Oliveira Brockington é Graduado em Física, Mestre em Ensino de Ciências e Doutor em Educação e professor da Universidade Federal do ABC. Disponível em: http://lattes.cnpq.br/9688530845451866. Acesso em: 10 jul. 2019.

42 Lucas Azevedo Mesquita Pereira é orientando de mestrado do Professor José Guilherme de Oliveira Brockington pelo Programa de Pós-graduação em Ensino de Ciências e Matemática. Disponível em: http://lattes.cnpq.br/8486566278399236. Acesso em: 10 jul. 2019.
} 


\section{RevistAleph}

da DC, um contraste com a boa divulgação científica, da qual os autores também tratam em seu trabalho. Entendemos que o uso desse adjetivo (má) demonstra que os autores reconhecem que nem todos os textos de DC seriam, para usar as palavras de Hilgartner (1990, p. 519), uma "distorção". Os autores demonstram que a boa divulgação científica pode ser alcançada e é, inclusive, tema de discussão entre os cientistas.

Os argumentos dos autores, ao longo das seções de nosso recorte, são corroborados por várias referências a outros autores que estudaram a DC, configurando efeitos dialógicos que são atravessados por outras vozes que ecoam como concordância ou discordância com a perspectiva de que há a má e a boa DC. A escolha por caracterizar entre "má" ou "boa" é uma marca linguística deixada pelos autores, demonstrando que a DC não é, de maneira geral, vista como uma "distorção" para a ciência. Os autores enfatizam a necessidade de se pensar estratégias que garantam a precisão da DC quanto aos resultados da ciência.

Os mecanismos enunciativos, essas marcas linguísticas, evidenciam a posição dos autores no artigo, assinalada pelo uso de verbos conjugados na primeira pessoa do plural "nós". Esse uso demonstra que há uma aproximação dos autores ao tema tratado no artigo. Alguns exemplos seriam: "acreditamos" (BROCKINGTON; MESQUITA, 2016, p. 33), "ressaltamos" (BROCKINGTON; MESQUITA, 2016, p. 31) e "apontaremos" (BROCKINGTON; MESQUITA, 2016, p. 29). Os autores trazem as referências teóricas para corroborar a argumentação, mas, ao mesmo tempo, posicionam-se junto a elas, proporcionando suas próprias impressões a respeito da DC.

$\mathrm{Na}$ introdução do artigo, os autores comentam sobre um surto de sarampo, que consequentemente teria trazido novas discussões a respeito do movimento antivacinação nos Estados Unidos. Os autores, então, questionam a razão de pais e mães estadunidenses decidirem por não vacinar seus filhos. A resposta para a questão seria o "papel da divulgação científica" (BROCKINGTON; MESQUITA, 2016, p. 29).

A apresentação de casos específicos para descrever a visão dominante da ciência foi o recurso usado por Hilgartner (1990, p. 520) e Green (1985, p. 141). No artigo em análise, Brockington e Mesquita (2016) retomam, em duas seções, alguns fatos relacionados a descobertas científicas que causaram impacto na sociedade nas últimas décadas. Um deles seria o movimento antivacinação. Podemos retomar a problemática de não considerar a totalidade dos sentidos. Conforme aponta Bakhtin (2017, p. 42), “não pode 


\section{RevistAleph}

haver um sentido único (um só) [...] ele está sempre situado entre os sentidos, é um elo na cadeia dos sentidos, a única que pode ser real em sua totalidade". Dessa forma, as concepções - sentidos - de DC não podem estar limitadas a certos fatos históricos em que ela foi protagonista na "distorção" do conhecimento científico, especialmente considerando que ela faz parte de uma esfera de produção de diversos gêneros que possibilitam à sociedade $o$ acesso às descobertas científicas.

Por outro lado, a seleção desses casos de "distorção" possui uma valoração. Como explica Bakhtin (2016, p. 47), as escolhas linguísticas são determinadas pelo tom valorativo, que é "a relação subjetiva emocionalmente valorativa do falante com o conteúdo do objeto e do sentido do seu enunciado". Há, na menção a esses casos, o que Volochínov (2013, p. 79) denomina de "parte subentendida" do enunciado. Os autores do artigo sob análise, ao relacionarem o surto do sarampo, entre outros casos, como consequência da DC, guiam o leitor, já na introdução do trabalho, a supor (subentender) que a DC representaria um "perigo" para a sociedade.

Trazendo a ideia de distanciamento de Bakhtin (2017, p. 18), podemos observar a relação de Brockington e Mesquita (2016) com a produção de DC. Os autores comentam, na seção As dificuldades da boa divulgação científica, que a DC "parte de cientistas, jornalistas científicos ou sem formação específica e, atualmente com os blogs, entusiastas do mundo da ciência" (BROCKINGTON; MESQUITA, 2016, p. 30). Os autores colocam-se numa posição de distanciamento se considerarmos que eles também são cientistas. Eles se distanciam do seu lugar de cientistas para observar o papel da DC na sociedade. Essa distância condiz com o princípio da exotopia (Bakhtin, 2003, p. 35). Para Bakhtin (2003, p. 35), a exotopia é a relação em que o autor de uma obra se coloca "fora de si mesmo [...]" e vê a si "pelo olhar do outro" no lugar do outro. Apesar de os autores não apresentarem soluções para a má divulgação científica, o excedente de visão proporciona a compreensão de que a DC "está suscetível a maus usos ou descuidos" (BROCKINGTON; MESQUITA, 2016, p. 31), ou seja, uma aproximação empática a respeito da DC.

Ainda na seção 2, os autores ressaltam a importância da linguagem na produção de DC, afirmando que adequá-la de uma maneira simplificada é "o maior dos desafios" (BROCKINGTON; MESQUITA, 2016, p. 30). Contudo, os autores não trazem, como demonstrado por eles na seção Mas como fazer uma boa divulgação científica?, uma solução para a questão da adequação da linguagem da DC. Pelo contrário, eles seguem o 


\section{RevistAleph}

parágrafo sobre a linguagem, na seção 2, propondo perguntas ao leitor: “Como simplificar sem perder o rigor ou induzir a erros? Como tornar atraente algo cuja validade e reconhecimento exigem um conjunto de conhecimentos distantes do cidadão comum?" (BROCKINGTON; MESQUITA, 2016, p. 30). Ao final, afirmam o seguinte: "Essas e outras perguntas estão no âmago da qualidade da DC" (BROCKINGTON; MESQUITA, 2016, p. 30). Porém, eles não proporcionam respostas. Vemos que essas perguntas não são objetivos do artigo em questão; elas constituem uma forma de diálogo com o leitor, mobilizando o outro. Nesse diálogo, há a compreensão responsiva de efeito retardado (BAKHTIN, 2016, p. 25). Os leitores não podem responder prontamente, mas são chamados a pensar a respeito e talvez, em um outro momento, escreverem um artigo que traga respostas.

O artigo sob análise foi publicado em uma revista de estudos de Biologia. Seus leitores são, provavelmente, adeptos desses estudos. É também provável que esses leitores não sejam cientistas da linguagem - linguistas - e possuam pouco ou nenhum conhecimento que possa responder às questões levantadas. Como aponta Volochínov (2013, p. 83), há uma situação (desconhecimento para responder às perguntas), que é compartilhada pelos autores e seus interlocutores, seu auditório social.

$\mathrm{Na}$ próxima seção, analisaremos o artigo da Linguista. Considerando nosso propósito, que é verificar as concepções de DC para a Linguística e para os demais campos de estudo, ao longo da seção seguinte, apontaremos alguns aspectos contrastivos no tratamento da DC entre ambos artigos.

\section{As concepções de DC sob o olhar valorativo da Linguística}

O artigo científico da área da Linguística que selecionamos para este trabalho intitula-se Características linguístico-discursivas da popularização da ciência ${ }^{43}$ de Cristina dos Santos Lovato ${ }^{44}$. Publicado na Revista Cenários no ano de 2014, o artigo tem como objetivo trazer "um inventário das características linguístico-discursivas da popularização da ciência" (LOVATO, 2014, p. 69). O artigo apresenta quatro seções: 1) Nota Introdutória;

\footnotetext{
43 LOVATO, Cristina dos Santos. Características linguístico-discursivas da popularização da ciência. Cenários, $\begin{array}{llllll}\text { v. } 2, \quad \text { n. } & 10, \quad 014 . & \text { Disponível }\end{array}$ https://seer.uniritter.edu.br/index.php?journal=cenarios\&page=article\&op=view\&path\%5B\%5D=979. Acesso em: 22 jun. 2019.

44 Doutora em Letras pela Universidade Federal de Santa Maria e professora na Universidade Federal do Pampa. Disponível em: http://lattes.cnpq.br/7562187381716677. Acesso em: 10 jul. 2019.
} 


\section{RevistAleph}

2) A ciência na mídia: jornalismo científico e popularização da ciência; 3) Características linguístico-discursivas da popularização da ciência; e 4) Considerações Finais.

O recorte realizado no artigo está constituído pelas seções 2 e 3 . A seção introdutória foi desconsiderada, pois apresentava o projeto de pesquisa do qual fazia parte o artigo, bem como outros estudos desenvolvidos, além de um breve resumo sobre a discussão ali proposta. Desconsideramos a seção Considerações Finais por apresentar uma síntese do trabalho e outros estudos a serem desenvolvidos.

Na seção 2 do artigo - A ciência na mídia: jornalismo científico e popularização da ciência -, a autora apresenta um contexto histórico sobre a DC a partir de referências a outros autores, fatos históricos que marcaram a sociedade, como a Primeira Guerra Mundial, e exemplos de revistas de DC. Para o Círculo de Bakhtin, o enunciado é visto como um continuum, que interage com passado e futuro. Sendo assim, a DC também se movimenta nessa rede de significações que emergem do contexto sócio-histórico. A autora dedica vários parágrafos para situar seu leitor no caminho percorrido pela DC. Cada parágrafo dialoga com alguma época da história que aponta para a disseminação do conhecimento por meio da DC.

Diferentemente do artigo de Brockington e Mesquita (2016, p. 29) que, como contexto-histórico, apresenta alguns exemplos que ressaltam a "má divulgação científica" relacionados às últimas décadas, o artigo de Lovato (2014, p. 70) busca fazer uma contextualização voltada para a DC como fonte de conhecimento para a sociedade. Observamos que essas diferentes formas de contextualizar a DC demonstram valorações que constroem seu sentido nos artigos e na visão de seus autores.

Uma vez apresentada a contextualização, a autora traz a definição de jornalismo científico, citando o "alto grau de especialização" (LOVATO, 2014, p. 72) que o jornalista deve ter. No artigo de Brockington e Mesquita (2016, p. 33), o jornalista também tem um papel crucial na produção da boa divulgação científica. Em ambos os artigos, o jornalista é visto como produtor de DC. Contudo, no artigo de Brockington e Mesquita (2016, p. 30), os autores afirmam que os cientistas também são produtores desses gêneros.

Nosso objetivo, neste trabalho, está orientado para as concepções de DC, independentemente da terminologia utilizada pelos autores. Contudo, ressaltamos o uso de jornalismo científico por Lovato (2014, p. 70). Em seu artigo, a autora o define como "a área responsável pela cobertura de tópicos relacionados à ciência e tecnologia [...]" 


\section{RevistAleph}

(LOVATO, 2014, p. 71). Conforme Volóchinov (2017, p. 205), é por meio da palavra que o indivíduo se define em relação ao outro. Assim, o ponto de vista da autora, pelo uso de certa terminologia, contextualiza seu trabalho na esfera de pesquisas sobre a $\mathrm{DC}$, bem como na linguagem da sua classe, do seu grupo social. Além disso, cada definição reflete e refrata o termo conforme as valorações de dado campo de estudos e do próprio autor que o emprega. Já Brockington e Mesquita (2016, p. 29) optam por utilizar o termo divulgação científica não como um tipo de texto em específico, mas como "reformulação do conhecimento científico para circular na sociedade [...]". Para eles, como mencionamos, os produtores também podem ser cientistas, bem como jornalistas, ou ainda, "entusiastas do mundo da ciência" (BROCKINGTON; MESQUITA, 2016, p. 30). Por tratar de jornalismo científico, o artigo de Lovato $(2014$, p. 70$)$ tem como produtor dos textos de DC somente o jornalista.

Enquanto, no artigo de Brockington e Mesquita (2016, p. 30), os autores apontam para a má divulgação científica como uma consequência da inexperiência de seus autores - cientistas, jornalistas, entre outros -, no artigo de Lovato $(2014$, p. 72), os jornalistas são os principais produtores da DC. Os cientistas são apresentados, em seu artigo, como "vozes [...] utilizadas pelos autores dos textos como recursos de autoridade [...]" (LOVATO, 2014, p. 76). Além disso, a partir de referencial teórico, a autora explica que a qualidade da DC pode estar relacionada ao medo que os jornalistas têm de questionarem os cientistas. Vemos, assim, diferentes excedentes de visão. Lovato (2014, p. 72), ao ressaltar o papel do jornalista, cria uma relação de empatia, que a coloca em uma posição de proximidade com ele, mas distancia-se para tratar dos aspectos linguísticos do texto de DC a partir de sua perspectiva de Linguista.

A visão dominante da ciência de Hilgartner (1990), apontada nos artigos sobre DC no Brasil, está presente no artigo de Lovato (2014, p. 73). A autora traz as questões já levantadas sobre a DC como "distorção" do conhecimento científico, argumentando que, de acordo com Hilgartner (1990, p. 520), a DC seria um recurso político para os cientistas. Por termos essa questão como motivação para nossa análise, observando ambos os recortes dos artigos, verificamos que, em Brockington e Mesquita (2016), não há qualquer menção à ciência como uma entidade superior, porém os autores trazem a ideia de conflito entre a ciência e o jornalismo. Apesar de não analisarmos o artigo como um todo, em uma das seções que tratam sobre relatos de casos, os autores, com base em referencial teórico, 


\section{RevistAleph}

comentam que alguns "neuromitos" - "interpretações equivocadas sobre a ciência do cérebro" (BROCKINGTON; MESQUITA, 2016, p. 32) - partem dos próprios laboratórios "devido ao uso exagerado, superficial ou desonesto de resultados publicados" (BROCKINGTON; MESQUITA, 2016, p. 32). Além disso, na seção 3, Mas como fazer uma boa divulgação científica?, os autores citam um evento que ocorreu, em 2014, com pesquisadores e editores da Revista Nature, no qual ressaltaram, como mais importante, a necessidade de atentar para a "transposição do resultado científico para o texto não acadêmico" (BROCKINGTON; MESQUITA, 2016, p. 33). Assim, observamos que os cientistas, ao contrário do que argumenta a visão dominante, também se colocam como responsáveis pela DC.

Ao pensarmos especificamente sobre a visão dominante, podemos ressaltar que o artigo de Lovato (2014) é marcado por valorações de outros autores que ressoam no trabalho. Ao citar os referenciais teóricos sobre a visão dominante, a autora concorda com essa posição. Como já ressaltamos, esses trabalhos que reforçam a visão dominante tornam as valorações mais constantes (VOLOCHÍNOV, 2013, p. 80), o que ocorre quando Lovato (2014, p. 74) replica o discurso de outros autores. Ela constrói seu discurso sobre a visão dominante, mas também permite que essa visão construa seu discurso. Podemos observar essa dinâmica, quando, na seção 3, a autora apresenta uma pesquisa sobre textos em português que preservaram "um discurso mais alinhado à visão dominante", enquanto os textos em inglês possuíam "um caráter contra-hegemônico" (LOVATO, 2014, p. 75). Esses discursos que potencializam a visão dominante, sem verificá-la, preenchem o olhar de outros estudiosos da DC. São palavras, enunciados e valorações que, por meio dessa relação dialógica dos discursos, penetram nos discursos de outrem e que:

[...] passaram pela experiência da expressão exterior em uma escala social maior ou menor, que foram por assim dizer socialmente bastante amoldados e polidos pelas relações e réplicas, pela reprovação ou apoio do auditório social (VOLÓCHINOV, 2017, p. 216).

Por fim, um dos vários aspectos a serem por nós percebidos é o destaque dado à linguagem, às "características linguístico-discursivas" no artigo de Lovato (2014, p. 69). Obviamente, sendo esse um artigo de uma Linguista, a linguagem da DC seria enfatizada. Brockington e Mesquita (2016, p. 30) afirmam que a linguagem "desempenha um papel fundamental", mas, provavelmente, por não serem cientistas da linguagem, não oferecem 


\section{RevistAleph}

soluções para o texto de DC. Apesar de perceberem a relevância da linguagem, não resgatam referenciais teóricos da Linguística. É, nesse sentido, que se respalda a constituição de nosso corpus com trabalhos de linguistas. Se a linguagem detém um papel crucial para a DC, é com base na Linguística que podemos nos apoiar para analisar as concepções de DC para professores-pesquisadores das demais áreas.

\section{Retomada e apontamentos}

Para observar o discurso do professor-pesquisador, é preciso ter em mente o contexto sócio-histórico da divulgação científica. Pensar a DC, a partir de seu contexto social e cultural, significa compreender o processo de produção concretamente. Como linguistas, já citamos a visão dominante da ciência em pesquisa (FETTER, 2017), replicando os discursos de outros linguistas que também estudam a DC. Porém, agora munidos de um novo olhar sobre o tema, precisamos sair de nosso lugar de linguistas e aproximarmo-nos do professor-pesquisador de outras áreas do conhecimento para que, nesse movimento exotópico, possamos ampliar nosso campo de visão.

Com base na análise do presente artigo, foi possível observar que há uma abertura para a DC entre os professores-pesquisadores. Sob o olhar de Brockington e Mesquita (2016), aqui tidos como "olhar da Física", a DC não é vista como "distorção" de maneira generalizada. Ao tratarem da DC como "boa" ou "má", os autores reconhecem que ela precisa ser produzida por profissionais capacitados que saibam adequar o discurso científico. Por outro lado, a escolha de relatos de casos em que a DC causou algum impacto negativo para a sociedade demonstra um posicionamento de contrariedade a esses gêneros do discurso. A DC, nos últimos anos, tem estado em processo de expansão, originando diversos estudos focados, especialmente, em sua linguagem. Brockington e Mesquita (2016, p. 30), inclusive, comentam que não há uma fórmula pronta para a boa DC, por isso textos desse gênero podem ser produzidos de maneira descontrolada. Percebemos que esses relatos de insucesso podem corroborar o discurso de professores-pesquisadores que são, de certa forma, contrários à DC.

Apesar de se tratar de um breve corpus de análise, as concepções de DC apresentadas sugerem que os professores-pesquisadores têm interesse nesse tema e preocupam-se com as consequências desses gêneros do discurso para a sociedade. Tal 


\section{RevistAleph}

inferência pode ser feita ao considerarmos que o artigo do periódico em estudos de Biologia foi publicado em um dossiê temático dedicado à DC, no qual vários professorespesquisadores abordaram o assunto. Além disso, em uma das seções do artigo em questão, os autores expõem alguns princípios para a produção de textos de DC que devem ser observados para minimizar as consequências do que os autores denominam de "má divulgação científica".

Dessa forma, podemos responder à hipótese proposta na introdução deste artigo. Mesmo que de maneira preliminar, a partir do corpus analisado, verificamos que há uma tendência, entre os professores-pesquisadores, em valorizar a DC como um instrumento relevante de comunicação com a sociedade. Esse movimento que prestigia a produção de DC entra em tensão com os discursos dos linguistas que atestam a visão dominante no Brasil, pois manifesta, para a Linguística, outra perspectiva a respeito da noção que os cientistas, de modo geral, têm sobre a DC.

Nosso objetivo, com o projeto de tese, partiu da necessidade de verificar a existência da visão dominante da ciência no Brasil. Cabe mencionarmos que nossa intenção não é contrapor os trabalhos já realizados que apresentam a visão dominante como uma característica constitutiva da DC, mas tê-los como motivação para proporcionar respostas que influenciem as pesquisas sobre o tema a tomar novos caminhos. Ao propor esse debate sobre a existência da visão dominante, pretendemos considerar a DC como um diálogo que não é estável, que pode passar por ressignificações vinculadas a seu contexto e tomar novas atitudes responsivas (VOLÓCHINOV, 2017, p. 232). Acreditamos que as universidades precisam assumir o protagonismo na produção de DC para que não seja apenas papel da mídia jornalística, possibilitando que a sociedade interaja, ainda mais, com as instituições científicas.

\section{Referências}

BAKHTIN, Mikhail. O autor e a personagem na atividade estética. In: BAKHTIN, M. Estética da criação verbal. 2. ed. Trad. Maria Ermantina Galvão G. Pereira. São Paulo: Martins Fontes: 1997.

BAKHTIN, Mikhail. Teoria do Romance I: a estilística. 1. ed. Trad. Paulo Bezerra. São Paulo: Editora $34,2015$.

BAKHTIN, Mikhail. Os gêneros do discurso. 1. ed. Trad. Paulo Bezerra. São Paulo: Editora 34, 2016. 


\section{RevistAleph}

BAKHTIN, Mikhail. Notas sobre literatura, cultura e ciência humanas. 1. ed. Trad. Paulo Bezerra. São Paulo: Editora 34, 2017.

BROCKINGTON, Guilherme; MESQUITA, Lucas. As consequências da má divulgação científica. Revista da Biologia, v. 15, n. 1, p. 29-34, 2016. Disponível em:

http://www.ib.usp.br/revista/node/207. Acesso em: 16 jan. 2019.

DI FANTI, Maria da Glória Corrêa. A linguagem em Bakhtin: pontos e pespontos. Veredas, Juiz de Fora, v. 7, n.1-2, p. 95-111, jan./dez., 2003. Disponível em:

https://periodicos.ufjf.br/index.php/veredas/article/view/25268. Acesso em: 19 jun. 2019.

FETTER, Giselle Liana. Divulgação tecnológica para agricultores familiares: análise de terminologias sob a ótica da linguística sistêmico-funcional. 2017. 535f. Dissertação (Mestrado em Estudos da Linguagem)- Universidade Federal do Rio Grande do Sul, Porto Alegre, 2017. Disponível em: http://www.lume.ufrgs.br/handle/10183/177686. Acesso em: 30 abr. 2018.

FETTER, Giselle Liana. Relações axiológicas da visão dominante da divulgação científica: análise dos discursos de linguistas brasileiros. In: SEMINÁRIO CÍRCULO DE BAKHTIN: ALTERIDADE, DIÁLOGO E DIALÉTICA, 2020, Porto Alegre. Anais [...]. No prelo.

GREEN, Jeremy. Media Sensationalisation and Science: The Case of the Criminal Chromosome. In: SHINN, T.; WHITLEY, R. (ed.). Expository Science: Forms and Functions of Popularisation. Boston: D. Reidel, 1985. p. 139-161.

HILGARTNER, Stephen. The Dominant View of Popularization: Conceptual Problems, Political Uses. Social Studies of Science, v. 20, n. 3, p. 519-539, ago. 1990. Disponível em: http://journals.sagepub.com/doi/abs/10.1177/030631290020003006. Acesso em: 6 jan. 2017.

LOVATO, Cristina dos Santos. Características linguístico-discursivas da popularização da ciência. Cenários, v. 2, n. 10, p. 69-81, 2014. Disponível em:

https://seer.uniritter.edu.br/index.php?journal=cenarios\&page=article\&op=view\&path\%5B\%5D=9 79. Acesso em: 22 jun. 2019.

MASSARANI, Luisa; MOREIRA, Ildeu de Castro. Science communication in Brazil: a historical review and considerations about the current situation. Anais da Academia Brasileira de Ciências, Rio de Janeiro, v. 88, n. 3, p. 1577-1595, 2016. Disponível em:

http://www.scielo.br/scielo.php?script=sci_arttext\&pid=S0001-37652016000401577. Acesso em: 25 maio 2019.

MASSARANI, Luisa; ROCHA, Mariana. Panorama general de la investigación en divulgación de la ciencia en América Latina. In: MASSARANI, L. et al. Aproximaciones a la investigación en divulgación de la ciencia en América Latina a partir de sus artículos académicos. Rio de Janeiro: Fiocruz - COC, 2017, p. 13-38.

MASSARANI, Luisa; ROCHA, Mariana. Ciência e mídia como campo de estudo: uma análise da produção científica brasileira. Intercom, São Paulo, v. 41, n. 3, p. 17-66, 2018. Disponível em: http://www.scielo.br/scielo.php?script=sci_arttext\&pid=S1809-

$58442018000300033 \& \operatorname{lng}=p t \& n r m=i s o \& t$ lng=pt. Acesso em: 25 maio 2019. 


\section{RevistAleph}

MYERS, Greg. Discourse studies of scientific popularization: questioning the boundaries. Discourse Studies, London, v. 5, n. 2, p. 265 - 279, 2003. Disponível em:

journals.sagepub.com/doi/abs/10.1177/1461445603005002006. Acesso em: 19

jan. 2017.

VOLOCHÍNOV, Valentín Nikoláievich. A construção da enunciação e outros ensaios. 1. ed. Trad. João Wanderley Geraldi. São Carlos: Pedro \& João Editores, 2013.

VOLOCHÍNOV, Valentín Nikoláievich. Marxismo e filosofia da linguagem: problemas fundamentais do método sociológico na ciência da linguagem. 1. ed. Trad. Sheila Vieira de Camargo Grillo. São Paulo: Editora 34, 2017.

ZAGO, Antônia; DI FANTI, Maria da Glória Corrêa. Palavras em operação: um dizer como trabalho, no trabalho e sobre o trabalho. Revista da Abralin, Curitiba, v. 7, n. 1, 2008. Disponível em:

https://revistas.ufpr.br/abralin/article/view/52616. Acesso em: 13 jul. 2019

Data do envio: $08 / 04 / 2020$

Data do aceite: 10/06/2020. 